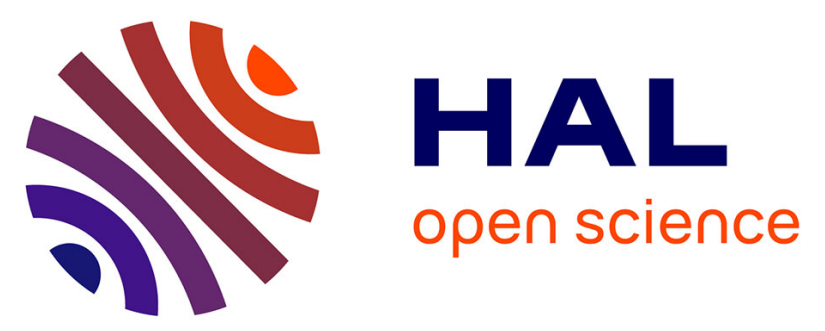

\title{
Optical properties and microstructure of 2.02-3.30 eV ZnCdO nanowires: Effect of thermal annealing
}

Manuel Lopez-Ponce, A. Hierro, J.-M. Ulloa, Pierre Lefebvre, E. Munoz, S. Agouram, V. Muñoz-Sanjosé, K. Yamamoto, A. Nakamura, J. Temmyo

\section{- To cite this version:}

Manuel Lopez-Ponce, A. Hierro, J.-M. Ulloa, Pierre Lefebvre, E. Munoz, et al.. Optical properties and microstructure of 2.02-3.30 eV ZnCdO nanowires: Effect of thermal annealing. Applied Physics Letters, 2013, 102, pp.143103. 10.1063/1.4799491 . hal-00809307

\section{HAL Id: hal-00809307 https://hal.science/hal-00809307}

Submitted on 24 Nov 2018

HAL is a multi-disciplinary open access archive for the deposit and dissemination of scientific research documents, whether they are published or not. The documents may come from teaching and research institutions in France or abroad, or from public or private research centers.
L'archive ouverte pluridisciplinaire $\mathbf{H A L}$, est destinée au dépôt et à la diffusion de documents scientifiques de niveau recherche, publiés ou non, émanant des établissements d'enseignement et de recherche français ou étrangers, des laboratoires publics ou privés. 


\title{
Optical properties and microstructure of 2.02-3.30 eV ZnCdO nanowires: Effect of thermal annealing
}

\author{
M. Lopez-Ponce, ${ }^{1}$ A. Hierro, ${ }^{1, a)}$ J. M. Ulloa, ${ }^{1}$ P. Lefebvre,,${ }^{1, b)}$ E. Muñoz, ${ }^{1}$ S. Agouram, ${ }^{2}$ \\ V. Muñoz-Sanjosé, ${ }^{2}$ K. Yamamoto, ${ }^{3}$ A. Nakamura, ${ }^{3}$ and J. Temmyo ${ }^{3}$ \\ ${ }^{1}$ ISOM and Dept. Ing. Electrónica, Univ. Politécnica Madrid, Avda. Complutense 30, 28040 Madrid, Spain \\ ${ }^{2}$ Department of Applied Physics and Electromagnetism, University Valencia, C/Dr. Moliner 50, \\ 46100 Burjassot, Spain \\ ${ }^{3}$ Research Institute of Electronics, Shizuoka University, 3-5-1 Johoku, Hamamatsu 432-8011, Japan
}

(Received 16 November 2012; accepted 20 March 2013; published online 8 April 2013)

\begin{abstract}
$\mathrm{ZnCdO}$ nanowires with up to $45 \% \mathrm{Cd}$ are demonstrated showing room temperature photoluminescence (PL) down to $2.02 \mathrm{eV}$ and a radiative efficiency similar to that of $\mathrm{ZnO}$ nanowires. Analysis of the microstructure in individual nanowires confirms the presence of a single wurtzite phase even at the highest $\mathrm{Cd}$ contents, with a homogeneous distribution of $\mathrm{Cd}$ both in the longitudinal and transverse directions. Thermal annealing at $550^{\circ} \mathrm{C}$ yields an overall improvement of the PL, which is blue-shifted as a result of the homogeneous decrease of Cd throughout the nanowire, but the single wurtzite structure is fully maintained. (c) 2013 American Institute of Physics. [http://dx.doi.org/10.1063/1.4799491]
\end{abstract}

The development of ZnO-based electronic and optoelectronic devices, both in thin films and nanostructures, has reached a point where using heterostructures has become necessary in order to tune the bandgap and thus control the injection and confinement of charge carriers. Indeed, by alloying with $\mathrm{Mg}$ or $\mathrm{Cd}$, the $\mathrm{ZnO}$ bandgap $(\sim 3.37 \mathrm{eV})$ can be theoretically changed from $\sim 7.8 \mathrm{eV}(\mathrm{MgO})$ to $\sim 2.3 \mathrm{eV}$ $(\mathrm{CdO}){ }^{1,2}$ However, in contrast to $\mathrm{ZnO}$, which shows a wurtzite structure, $\mathrm{CdO}$ and $\mathrm{MgO}$ naturally show a rocksalt structure, and thus 7.8 and $2.3 \mathrm{eV}$ correspond to the direct bandgap of the rocksalt phases of $\mathrm{MgO}$ and $\mathrm{CdO}$, respectively. This transition from wurtzite to rock-salt leads to phase separation in the alloys, limiting the maximum amount of $\mathrm{Cd}$ or $\mathrm{Mg}$ that can be incorporated into $\mathrm{ZnO} .{ }^{3,4} \mathrm{In}$ the particular case of $\mathrm{Cd}$, the high vapour pressure and low thermodynamic solid solubility ( $\sim 2 \%)$ pose an additional problem for the realization of $\mathrm{ZnCdO}$ layers with high $\mathrm{Cd}$ contents. Although thin films with $\mathrm{Cd}$ contents up to $\sim 69.7 \%$ have been demonstrated with wurtzite structure using remoteplasma-enhanced metal-organic chemical vapour deposition (RPE-MOCVD), ${ }^{5}$ most published reports do not reach higher Cd contents than $10 \%-15 \%$, probably as a result of this phase separation problem. ${ }^{6}$ Besides, the fabrication of a device using these alloys adds an additional problem: the postgrowth thermal budget resulting from ohmic contact annealing, dopant activation, or point defect reduction, through thermal annealing. Indeed, several groups have reported the use of thermal annealing in the $500-800{ }^{\circ} \mathrm{C}$ range to decrease the ohmic contact resistance to $\mathrm{ZnO},{ }^{7}$ whereas others have used annealing as high as $850-900^{\circ} \mathrm{C}$ to increase the carrier mobility ${ }^{8}$ or to activate p-type dopants. ${ }^{9}$ Because of the low growth temperatures used for $\mathrm{ZnCdO}$, which are in the $300-500^{\circ} \mathrm{C}$ range, ${ }^{10,11}$ these post growth annealing processes are likely to induce structural, electrical, and optical

\footnotetext{
${ }^{a)}$ Electronic mail: adrian.hierro@upm.es

${ }^{b)}$ Now at Laboratoire Charles Coulomb, CNRS, Université Montpellier 2, Montpellier, France.
}

changes in the alloys. These changes need to be accounted for and understood, especially for the case of $\mathrm{ZnCdO}$, since Cd has a strong tendency to diffuse. ${ }^{12}$

In the present study, we have used a combination of photoluminescence (PL), high resolution x-ray diffraction (HRXRD), high resolution transmission electron microscopy (HRTEM), and micro energy dispersive x-ray spectroscopy (micro-EDX) to quantitatively analyze the incorporation of $\mathrm{Cd}$ in $\mathrm{ZnCdO}$ nanowires with wurtzite structure, as well as the impact that post-growth thermal annealing has on their microstructure and radiative efficiency.

Vertically aligned c-axis $\mathrm{ZnCdO}$ nanowires were grown at $300^{\circ} \mathrm{C}$ on a-plane sapphire substrates by RPE-MOCVD. Details on the growth can be found in Ref. 13. A series of four samples with nominal $\mathrm{Cd}$ concentrations ranging from $\mathrm{x}=0$ to 0.45 were studied. The nanowires were typically 1-3 $\mu \mathrm{m}$-long and $100-200 \mathrm{~nm}$-wide. A representative plan and cross sectional view of the nanowires are shown in Fig. 1. This set of samples was exposed to a rapid thermal annealing (RTA) cycle in a $\mathrm{N}_{2}$ atmosphere with temperatures ranging from 250 to $550^{\circ} \mathrm{C}$ for varying times. Continuous-wave PL spectroscopy at room temperature and under vacuum conditions was done in backscattering configuration by using a He-Cd laser $(\lambda=325 \mathrm{~nm})$ under constant power density excitation. The crystal microstructure and $\mathrm{Cd}$ concentration profiles of the self-aligned nanowires were assessed by HRXRD scans around the [0001] reflections using an X'Pert PRO PANalytical diffractometer. HRTEM and micro-EDX were performed on individual nanowires using a fieldemission TECNAI G ${ }^{2}$ F20 microscope (from FEI) operated at $200 \mathrm{kV}$. In order to avoid any possible influence of the sample inhomogeneity on the analysis, both the optical and structural characterizations were performed in the same sample piece before and after annealing.

As shown in Figures 2 and 3, the room temperature near-band-edge PL energy red-shifts with increasing Cd content down to $2.02 \mathrm{eV}$, for $45 \% \mathrm{Cd}$, covering a large part of the visible spectrum. The fact that a lower emission energy 


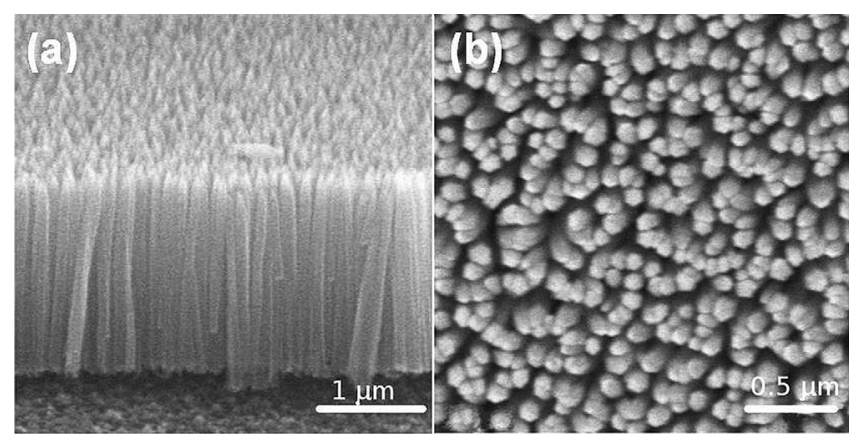

FIG. 1. Plan view (a) and cross-sectional view (b) SEM images of the asgrown $\mathrm{Zn}_{0.73} \mathrm{Cd}_{0.27} \mathrm{O}$ nanowires.

than the bandgap of $\mathrm{CdO}$ is obtained is likely the result of the large Stokes shifts present in this alloy. ${ }^{13}$ Even though the PL full width at half maximum (FWHM) increases when adding $\mathrm{Cd}$ to $\mathrm{ZnO}$, it is worth noticing that the PL peak intensity at room temperature is not strongly affected by the $\mathrm{Cd}$ content. Indeed, the $\mathrm{PL}$ intensity in the $\mathrm{ZnCdO}$ nanowires is quite similar to that of the $\mathrm{ZnO}$ nanowires even for emission energies as low as $2.02 \mathrm{eV}$ (Fig. 2). The increase in FWHM as $\mathrm{Cd}$ is added to $\mathrm{ZnO}$ is the well-known effect of exciton localization on potential fluctuations induced by natural alloy disorder. ${ }^{13,14}$ Indeed, Buyanova et al. ${ }^{14}$ showed that this was the case for $\mathrm{ZnCdO}$ samples with $9 \%$ and $15.7 \% \mathrm{Cd}$ and proposed that increasing the $\mathrm{Cd}$ content leads to a decrease of the exciton binding energy and, therefore, to an increase of the Bohr radius. The latter can then lead to a larger tunnelling probability between the band tail states, thus leading to a larger PL FWHM in $\mathrm{ZnCdO}$ versus $\mathrm{ZnO}$. The Stokes shift observed by Buyanova et al. was constant in the $9 \%-15.7 \% \mathrm{Cd}$ range. In contrast, we observe that the FWHM not only increases from $\mathrm{ZnO}$ to $\mathrm{ZnCdO}$ but actually depends on $\mathrm{Cd}$ and shows a maximum value for $\sim 20 \% \mathrm{Cd}$. In fact, Yamamoto et al. ${ }^{13}$ showed that in $\mathrm{ZnCdO}$ films, the effect of alloy disorder is maximum for $\mathrm{Cd}$ concentrations around 20\%-30\%, leading to a maximum in the Stokes shift and PL FWHM, alike the behaviour here observed. Thus, we can conclude that the presence of $\mathrm{Cd}$ induces a larger PL

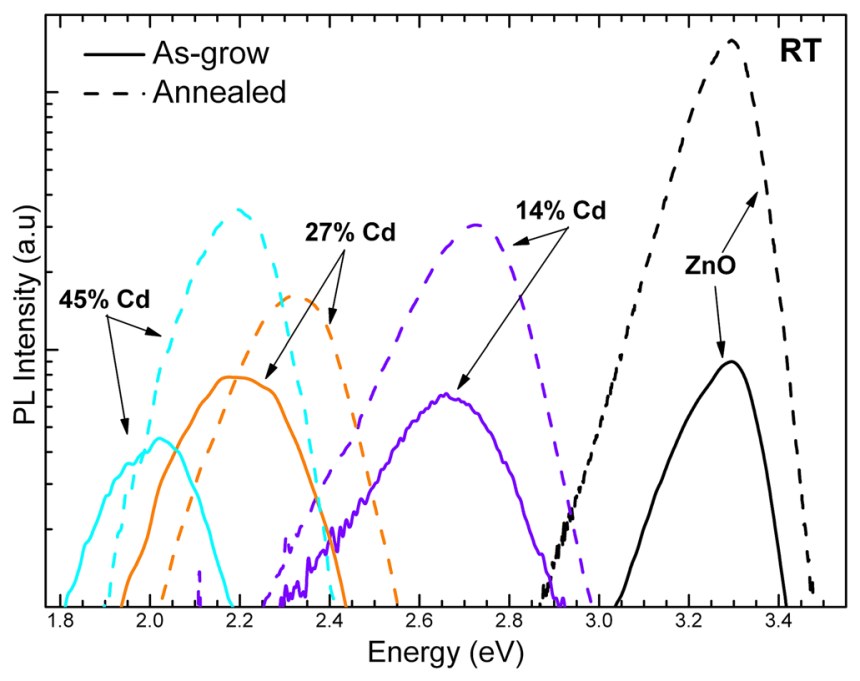

FIG. 2. Room temperature photoluminescence spectra of the as-grown and annealed $\mathrm{ZnCdO}$ nanowires for different $\mathrm{Cd}$ contents, as indicated.
FWHM likely as a result of both localization potential (induced by alloy disorder) and increased Bohr radius.

Choosing the sample with the intermediate $27 \% \mathrm{Cd}$ content as a representative sample of the series, we can observe in Fig. 3(b) the effect that the RTA temperature has on the PL. The RTA time was also varied from 1 to $5 \mathrm{~min}-$ not shown-and it was found that the entire enhancement in PL intensity takes place during the first minute, reason why this cycle time was used for the rest of the study. The peak energy exhibits a significant blue shift only for the largest annealing temperature, i.e., $550{ }^{\circ} \mathrm{C}$, while the PL intensity is actually enhanced as soon as the growth temperature $\left(300^{\circ} \mathrm{C}\right)$ is exceeded. The improvement in PL intensity for the intermediate annealing temperatures, i.e., 400 and $500{ }^{\circ} \mathrm{C}$, is likely linked to the reduction of non-radiative channels via the decrease in concentration of the most common point defects found in $\mathrm{ZnO}$, which for highly n-type material like in our case, are $\mathrm{Zn}$ vacancies $\left(\mathrm{V}_{\mathrm{Zn}}\right)$ and/or complexes involving this type of point defects. ${ }^{15,16}$ For these annealing temperatures $\left(400-500{ }^{\circ} \mathrm{C}\right)$, there is only a small blue shift, and thus the targeted PL emission energy is mostly maintained but with enhanced radiative emission. Hence, the $400-500{ }^{\circ} \mathrm{C}$ range seems appropriate for annealing ohmic contacts on $\mathrm{ZnCdO}$. At $550{ }^{\circ} \mathrm{C}$, there is already a sizeable PL blue-shift as well as a large reduction of the PL FWHM. Since this temperature is also close to the upper limit typically used for ohmic contact annealing in this type of oxides, it was chosen for the quantitative analysis of the Cd concentration profiles and microstructure after annealing.

The aforementioned enhancement of the PL intensity upon annealing is larger in the reference $\mathrm{ZnO}$ sample than in the $\mathrm{Cd}$-containing ones, and in fact the $27 \% \mathrm{Cd}$ sample shows the lowest enhancement (Fig. 3(a)). This effect can be explained to result from the stronger localization of the exciton when $\mathrm{Cd}$ is present, especially for the $27 \% \mathrm{Cd}$ sample, where the effect of alloy disorder is maximum. ${ }^{13}$ Under these

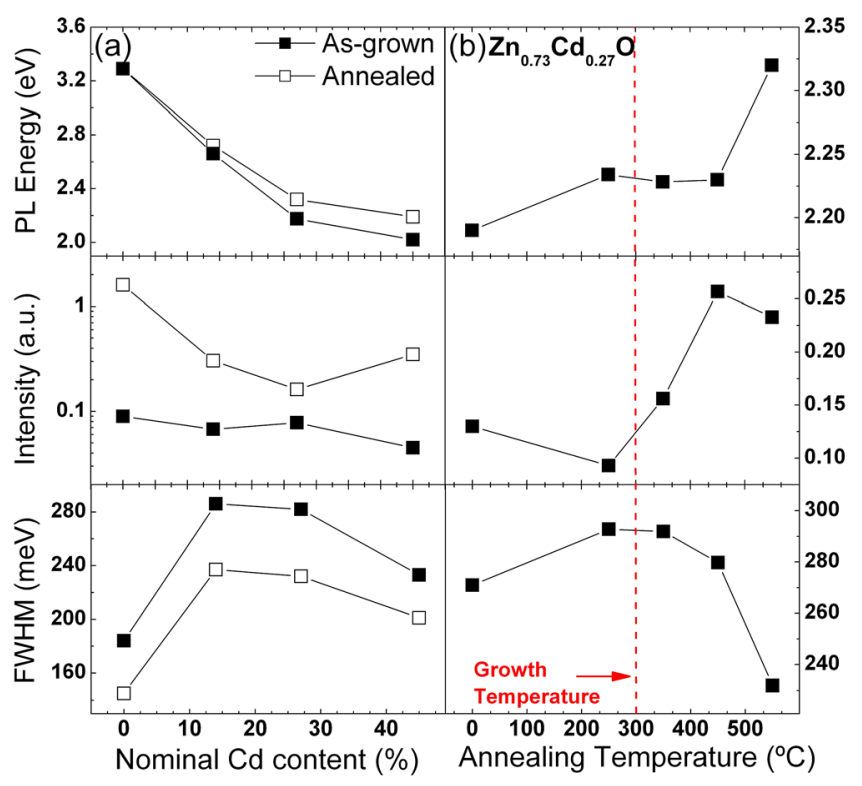

FIG. 3. (a) Dependence on Cd content of the RT-PL peak energy, intensity and FWHM, both for the as-grown and annealed nanowires. (b) Dependence on annealing temperature of the PL properties for the $\mathrm{Zn}_{0.73} \mathrm{Cd}_{0.27} \mathrm{O}$ nanowires. The annealing time was $1 \mathrm{~min}$. Connecting lines are a guide to the eye. 
strong localization conditions, the exciton is less sensitive to the reduction of non-radiative recombination paths upon annealing, and thus the radiative emission is only lightly affected. The stronger reduction of the PL FWHM in the samples with $14 \%$ and $27 \% \mathrm{Cd}$ is likely related to decreasing the degree of alloy disorder after annealing. Annealing also induces a PL blue shift that increases with the Cd content, reaching $170 \mathrm{meV}$ for the nanowires with $45 \% \mathrm{Cd}$, and whose origin is discussed below in terms of the nanowire microstructure.

As mentioned in the introduction, increasing the $\mathrm{Cd}$ content in $\mathrm{ZnCdO}$ above 15\%-20\% typically leads to phase separation and a mixed wurtzite/rock-salt phase appears. ${ }^{3}$ This effect has traditionally limited the spectrum energies that can be covered with $\mathrm{ZnCdO}$ to values not far from that of the $\mathrm{ZnO}$ bandgap. This limitation is even more pronounced when this ternary alloy is exposed to a thermal annealing cycle, especially at high temperatures, where the diffusion of $\mathrm{Cd}$ is enhanced allowing the formation of the rocksalt phase. $\mathrm{So}$, as a first step, the $\mathrm{Cd}$ content of the as-grown nanowires was measured by EDX. To do so, the nanowires were removed from the substrate and deposited on a TEM grid. The mean $\mathrm{Cd}$ content was then obtained for each sample by analyzing the EDX signal from ensembles of tens of nanowires (by defocusing the microscope spot to include the signal from many nanowires), thus averaging out possible inhomogeneities in the $\mathrm{Cd}$ profile within the nanowire as well as among different nanowires. The resulting measured $\mathrm{Cd}$ content is shown in the X-axis of Fig. 6(b) and has an error bar of $\pm 2.5 \%$, mostly given by the EDX concentration resolution $(\sim 2 \%)$. As shown in Fig. 6, the measured Cd concentrations matched well the nominal ones for all samples. In addition, HRTEM analysis of as-grown single nanowires only shows the presence of the wurtzite crystal structure, even for the nanowires with $45 \% \mathrm{Cd}$, contrary to what is typically reported in the literature. Figs. 4(a) and 4(b) show
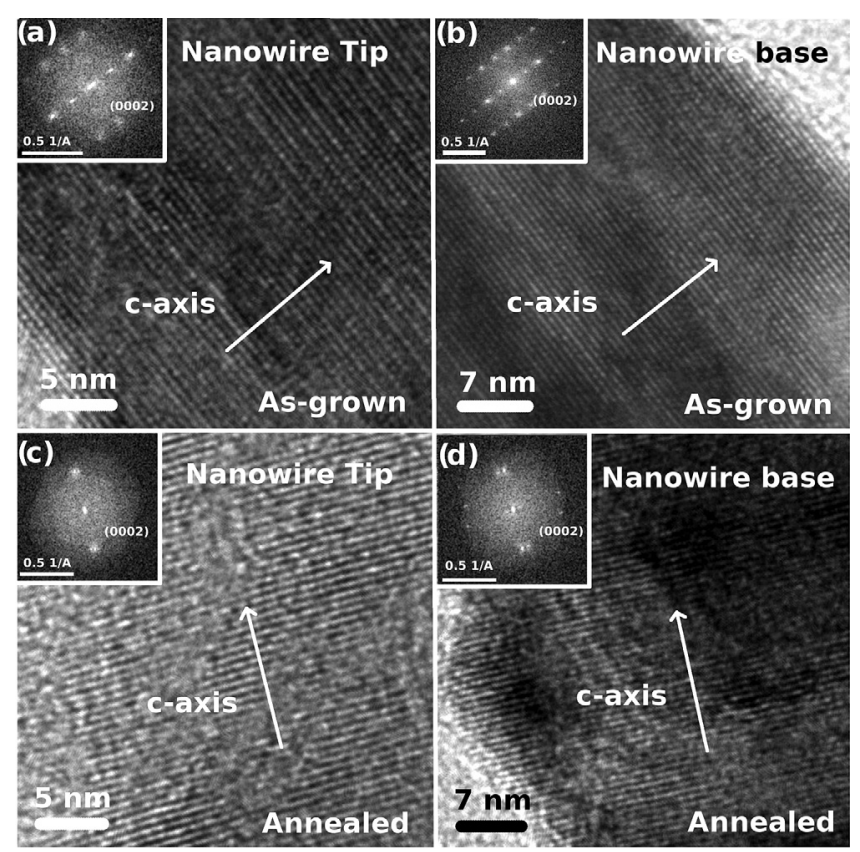

FIG. 4. HRTEM images of two $\mathrm{Zn}_{0.73} \mathrm{Cd}_{0.27} \mathrm{O}$ nanowires, (a), (b) as-grown, and (c), (d) annealed. The insets show the FFT of the diffraction pattern. typical HRTEM images and diffraction patterns of the nanowire tip and base for the intermediate $27 \% \mathrm{Cd}$ sample, as a representative example. No trace of crystal phase separation is observed. An analysis of the crystal plane separation through the fast Fourier transform (FFT) of the diffraction pattern does show a reduction of the lattice parameter closer to the surface, base, and tip of the nanowires, indicating a reduction of $\mathrm{Cd}$ content in these regions, consistent with its low vapour pressure and the difficulty to incorporate it in the lattice. However, the rock-salt phase is not observed even for $45 \%$ Cd contents.

To confirm the Cd concentration profile within the nanowire, micro-EDX was performed along the longitudinal and transverse axes of individual nanowires of each sample. The performed microanalysis has a spatial resolution of $\sim 2 \mathrm{~nm}$ and a concentration resolution of $\sim 2 \%$. Figure 5(a) shows the $\mathrm{Cd}$ and $\mathrm{Zn}$ profiles for the as-grown $27 \% \mathrm{Cd}$ sample, where we can observe that the $\mathrm{Cd}$ distribution is homogeneous along the nanowire. Also, across the nanowire, the $\mathrm{Cd}$ content decreases closer to the surface, in agreement with what was observed by HRTEM in the measurement of the atomic plane separation. The fact that the $\mathrm{Cd}$ and $\mathrm{Zn}$ concentration profiles are anticorrelated and add up to be one is a good indication that this result is not a measurement artefact. In addition, $\mathrm{Cd}$ is not observed to accumulate in any specific regions, even for the highest Cd content of $45 \%$. Similar results were obtained for all Cd-containing samples.

Analyzing the annealed nanowires by HRTEM, it is observed that the wurtzite microstructure is completely maintained (Figs. 4(c) and 4(d)), and no traces of the rocksalt crystal structure are observed, regardless of the $\mathrm{Cd}$ content. What micro-EDX indeed shows (Fig. 5(b)) is that the homogeneous distribution of $\mathrm{Cd}$ along and across the nanowire remains after annealing, and the same $\mathrm{Cd}$ deficiency as in the as-grown nanowires is observed closer to the nanowire surface. The

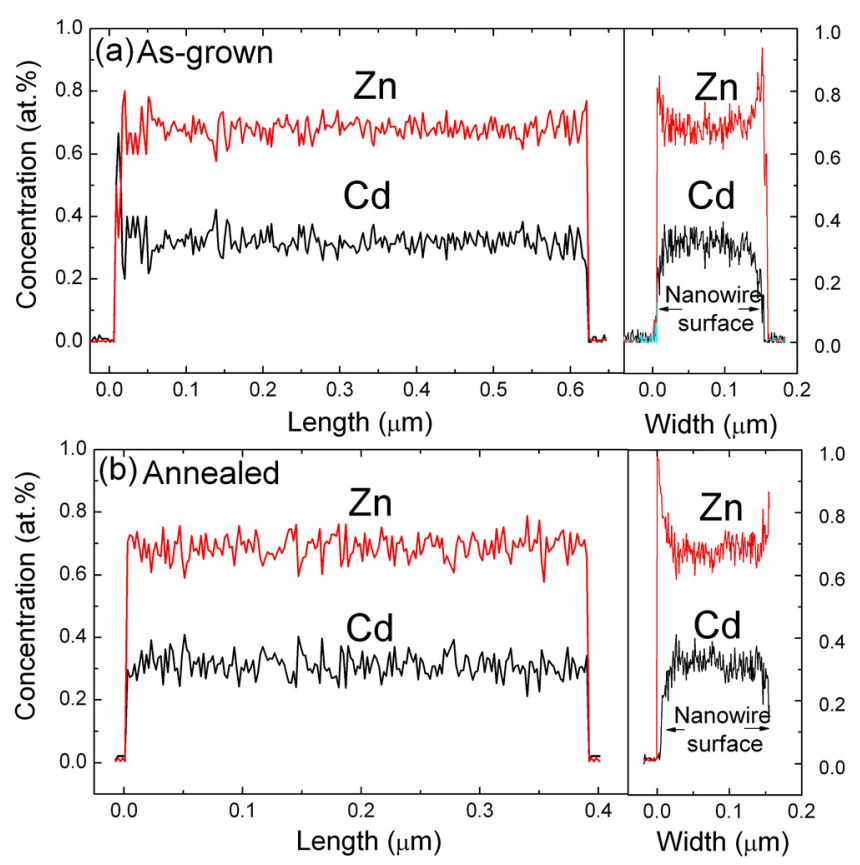

FIG. 5. $\mathrm{Cd}$ and $\mathrm{Zn}$ concentration profiles of two individual $\mathrm{Zn}_{0.73} \mathrm{Cd}_{0.27} \mathrm{O}$ nanowires, (a) as-grown and (b) annealed, measured along and across the nanowire by micro-EDX. 

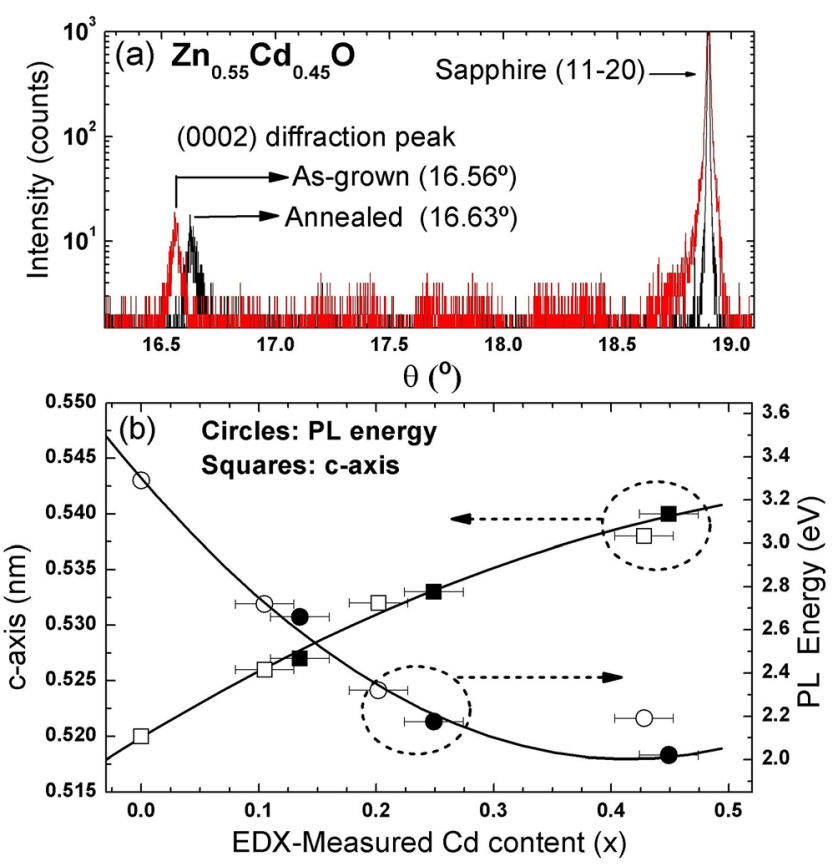

FIG. 6. (a) HRXRD diffraction pattern for the as-grown and annealed $\mathrm{Zn}_{0.55} \mathrm{Cd}_{0.45} \mathrm{O}$ nanowires. (b) Dependence of the c-axis lattice parameter (extracted from HRXRD) and PL energy, on the Cd content determined by EDX on both as-grown (solid symbols) and annealed (hollow symbols) samples. Note that for $\mathrm{x}=0$ (pure $\mathrm{ZnO}$ ), the measured PL energy and c-axis lattice parameter were identical for the as-grown and annealed samples. The solid lines are quadratic fits to the experimental data.

similar Cd contents observed in Fig. 5 between the as-grown and annealed nanowires are the result of the large error bar in the EDX measurement, which masks this variation. In fact, and as mentioned before, the changes in the $\mathrm{Cd}$ concentration between as-grown and annealed nanowires are only observable when the signal from ensembles of tens of nanowires is measured, yielding the results shown in Fig. 6(b). The general reduction of the $\mathrm{Cd}$ content taking place during annealing can be explained to result from out-diffusion to the surface of this element followed by evaporation. Indeed, Azarov et al. ${ }^{17}$ showed that upon annealing at high temperatures, $\mathrm{ZnCdO}$ films with $7 \% \mathrm{Cd}$ also show a significant evaporation of $\mathrm{Cd}$ through the surface and that above $600{ }^{\circ} \mathrm{C}$, the diffusion of $\mathrm{Cd}$ already begins. In the case of nanowires, where the surface/ volume ratio is large, the $\mathrm{Cd}$ atoms have to diffuse a short distance to be able to evaporate, reason why such a pronounced effect is already observed at $550^{\circ} \mathrm{C}$.

The change in lattice parameter of the nanowires upon annealing was also confirmed with HRXRD of the vertically aligned nanowires. Figure 6(a) shows a representative example of the diffraction pattern along the (0001) direction, and it can clearly be observed how the $\mathrm{ZnCdO}$-related peak shifts upon annealing as a result of the change of the c-axis lattice parameter, again indicative of the reduction of $\mathrm{Cd}$ in the annealed nanowires. The resulting c-axis lattice parameters of all samples as a function of the EDX-measured Cd content are shown in Fig. 6(b). A quadratic fit to the data, including both as-grown and annealed nanowires, yields the relation $\mathrm{c}(\mathrm{nm})=0.520+0.064 \mathrm{x}-0.044 \mathrm{x}^{2}$, quite similar to previous references in as-grown thin films (Refs. 13 and 18). Therefore, the c-axis is univocally determined by the $\mathrm{Cd}$ content, regardless of the exposure of the nanowires to thermal annealing. In addition, by plotting the measured PL peak energy as a function of the measured $\mathrm{Cd}$ content, we see a good match for both as-grown and annealed samples. Using also a quadratic fit to the experimental data, the evolution of the $\mathrm{Zn}_{\mathrm{x}} \mathrm{Cd}_{1-\mathrm{x}} \mathrm{O}$ near band edge emission follows the expression $\mathrm{E}(\mathrm{eV})=3.30-6.26 \mathrm{x}+7.56 \mathrm{x}^{2}(0 \leq \mathrm{x} \leq 0.45)$. Thus, the blue-shift of the PL energy upon annealing can be univocally assigned to an overall reduction of $\mathrm{Cd}$ content in the nanowire while maintaining the wurtzite structure.

In order to relate the PL energy to the $\mathrm{Cd}$ content within the nanowire, one needs to account for several effects. In $\mathrm{ZnO}$ nanowires, a charge depletion region exists at the surface $^{19}$ confining the carriers within the nanowire core. This effect is likely reduced in $\mathrm{ZnCdO}$ since the residual n-type concentration is typically larger than in $\mathrm{ZnO}$, and so the surface-related depletion region should be thinner. However, as we showed above, there is a $\mathrm{Cd}$ depletion close to the surface both in as-grown and annealed nanowires, effect that would create an additional potential barrier that further confines the carriers within the nanowire. Thus, the PL emission energy has to be linked to the measured $\mathrm{Cd}$ content within the core of the nanowire.

In conclusion, we have demonstrated $\mathrm{ZnCdO}$ nanowires with room temperature PL energies covering the spectral region from $3.3 \mathrm{eV}$ down to $2.02 \mathrm{eV}$, corresponding to a measured $\mathrm{Cd}$ concentration in the nanowire from $0 \%$ to $45 \%$. Moreover, all nanowires show a wurtzite structure with no indication of crystal phase separation or $\mathrm{Cd}$ accumulation. These nanowires have radiative efficiencies that compare well to that of the reference $\mathrm{ZnO}$ nanowires. Even though the growth temperature is quite low in these nanowires $\left(300^{\circ} \mathrm{C}\right)$, thermal annealing up to $550{ }^{\circ} \mathrm{C}$ may be used in future device processing. Indeed, after a $550{ }^{\circ} \mathrm{C}$ annealing, the single wurtzite structure is completely maintained even with $45 \% \mathrm{Cd}$, and the only detrimental effect is the PL blue shift that arises from a homogeneous reduction of $\mathrm{Cd}$ along and across the nanowire, which is lost through evaporation.

The authors would like to thank T. Brazzini for assistance with the XRD measurements and gratefully acknowledge the support of the Ministry of Economy and Competitiveness (MINECO) and the EU (FEDER) through Project No. TEC2011-28076-C02-01/02, the MINECO-Japanese Science and Technology Agency (JST) Project No. PIB2010JP-00279, the Generalitat Valenciana under Project Nos. Prometeo/2011035 and ISIC/2012/008, and the Institute of Nanotechnologies for Clean Energies of the Generalitat Valenciana.

${ }^{1}$ K. Takahashi, A. Yoshikawa, and A. Sandhu, Wide Bandgap Semiconductors: Fundamental Properties and Modern Photonic and Electronic Devices (Springer, 2007).

${ }^{2}$ F. P. Koffyberg, Phys. Rev. B 13, 4470 (1976).

${ }^{3}$ K. Sakurai, T. Takagi, T. Kubo, D. Kajita, T. Tanabe, H. Takasu, Sz. Fujita, and Sg. Fujita, J. Cryst. Growth 514, 237 (2002).

${ }^{4}$ W. I. Park, G.-C. Yi, and H. M. Jang, Appl. Phys. Lett. 79, 2022 (2001).

${ }^{5}$ S. Shigemori, A. Nakamura, J. Ishihara, T. Aoki, and J. Temmyo, Jpn. J. Appl. Phys., Part 2 43, L1088 (2004).

${ }^{6}$ F. Bertram, S. Giemsch, D. Forster, J. Christen, R. Kling, C. Kirchner, and A. Waag, Appl. Phys. Lett. 88, 061915 (2006).

${ }^{7}$ L. J. Mandalapu, Z. Yang, and J. L. Liu, Appl. Phys. Lett. 90, 252103 (2007). ${ }^{8}$ K. K. Kim, S. Niki, J. Y. Oh, J. O. Song, T. Y. Seong, S. J. Park, S. Fujita, and S. W. Kim, J. Appl. Phys. 97, 066103 (2005). 
${ }^{9}$ C. C. Lin, C. Y. Chen, S. Y. Cheng, S. Y. Cheng, and H. Y. Lee, Appl. Phys. Lett. 84, 5040 (2004).

${ }^{10}$ J. Ishihara, A. Nakamura, S. Shigemori, T. Aoki, and J. Temmyo, Appl. Phys. Lett. 89, 091914 (2006).

${ }^{11}$ T. Ohashi, K. Yamamoto, A. Nakamura, and J. Temmyo, Jpn. J. Appl. Phys., Part 1 47, 2961 (2008).

${ }^{12}$ A. V. Thompson, C. Boutwell, J. W. Mares, W. V. Schoenfeld, A. Osinsky, B. Hertog, J. Q. Xie, S. J. Pearton, and D. P. Norton, Appl. Phys. Lett. 91, 201921 (2007).

${ }^{13}$ K. Yamamoto, T. Tsuboi, T. Ohashi, T. Tawara, H. Gotoh, A. Nakamura, and J. Temmyo, J. Cryst. Growth 312, 1703 (2010).
${ }^{14}$ I. A. Buyanova, J. P. Bergman, G. Pozina, W. M. Chen, S. Rawal, D. P. Norton, S. J. Pearton, A. Osinsky, and J. W. Dong, Appl. Phys. Lett. 90, 261907 (2007).

${ }^{15}$ T. M. Børseth, B. G. Svensson, A. I. Kuznetsov, P. Klason, Q. X. Zhao, and M. Willander, Appl. Phys. Lett. 89, 262112 (2006).

${ }^{16}$ A. Janotti and C. G. Van de Walle, Rep. Prog. Phys. 72, 126501 (2009).

${ }^{17}$ A. Y. Azarov, T. C. Zhang, B. G. Svensson, and A. Y. Kuznetsov, Appl. Phys. Lett. 99, 111903 (2011).

${ }^{18}$ T. Makino, Y. Segawa, M. Kawasaki, A. Ohtomo, R. Shiroki, K. Tamura, T. Yasuda, and H. Koinuma, Appl. Phys. Lett. 78, 1237 (2001).

${ }^{19}$ Z. Liao, K. Liu, J. Zhang, J. Xu, and D. Yu, Phys. Lett. A 367, 207 (2007). 